\title{
Electrocardiographic approach to classification of acute pericarditis in emergency department: Typical and atypical pericarditis
}

\author{
Ersin Saricam*, MD, Yasemin Saglam, MD
}

Saricam E, Saglam Y. Electrocardiographic approach to classification of acute pericarditis in emergency department: Typical and atypical pericarditis. Curr Res Cardiol 2018;5(2):23-5.

BACKGROUND: In typical pericarditis, concave ST-segment elevation can be characteristically seen in electrocardiogram (ECG). However, PR-segment depression may be the earliest ECG change in patients with acute pericarditis and in following time, from atypical pattern to typical pattern transition may be occur. Without ST-segment elevation in ECG may undergo misdiagnosed or overestimated condition, including acute coronary syndrome. Therefore, we classified acute pericarditis by highlighting ECG features to prevent any possible failure to notice acute pericarditis in emergency department (ED).

METHODS: This study included 216 patients selected from the 2140 patients acute chest pain admitted into ED between 2015 and 2018. The two groups were retrospectively created by virtue of the presence or absence of typical ECG findings. Typical ECG refers to diffuse or regional concave ST-segment elevations with reciprocal ST-segment depression in aVR, and V1 in ECG, and atypical ECG refers to PR-segment depression in leads V5 to V6 in ECG
100 patients (group I) had typical ECG, whereas 116 patients (group II) had atypical ECG changes.

RESULTS: The mean age of the patients with typical pericarditis was higher than those with atypical pericarditis $(\mathrm{P}<0.05)$. Typical pericarditis group had higher CRP level $(\mathrm{P}<0.05)$. Atypical pericarditis group had more recurrence rate than typical pericarditis $(\mathrm{P}<0.05)$. In ECG following time, 10 patients with the atypical pericarditis pattern were transformed typical pericarditis pattern.

CONCLUSION: We classified acute pericarditis as typical and atypical by highlighting ECG features to prevent any possible failure to notice acute pericarditis. Thanks to PR-segment recognition, acute pericarditis diagnosis may confirm and prevent the inappropriate coronary intervention. It is recommended that the ECG features should be examined thoroughly, especially with a focus on ST-segment elevation besides PR-segment depression.

Key Words: Acute pericarditis; ST-segment elevation; PR-segment depression; Atypical pericarditis

\begin{abstract}
A cute pericarditis is a disease caused by the inflammation of the pericardium (1). Pericarditis is responsible for $0.1 \%$ of all hospital admissions and $5 \%$ of emergency department (ED) admissions for chest pain (2-4). The clinical diagnosis of acute pericarditis can be made with 2 of the 4 criteria according to the 2015 European Society of Cardiology guideline of pericardial diseases (5). These criteria are typical chest pain, pericardial friction rub, pericardial effusion (new or worsening), and electrocardiographic changes.

ECG interpretation is an essential part of evaluation of patients with chest pain symptoms. The characteristic electrocardiogram (ECG) findings in patients with acute pericarditis are a diffuse elevation of the ST-segment. Historically, in 1973, ECG changes were defined by Spodick (6) in 4 stages, including ECG findings in a patient with acute pericarditis progressing from ST elevations to T-wave inversion and returning to baseline ECG. However, the typical ECG changes with ST-elevation have been reported in up to $60 \%$ of the cases (7). The rest of the patients, those with atypical ECG (elevation of PR segment in lead aVR and depression of PR segment in other leads, especially in leads V5 and V6), had no ST elevations. PR-segment depression may be the earliest ECG change in patients with acute pericarditis and in following time, from atypical pattern to typical pattern transition may be occur (8).
\end{abstract}

The classic and most common complaint of patients with pericarditis is chest pain called sharp and pleuritic. If ST-segment elevation in ECG seems not to exist, acute pericarditis may easily be missed even if typical chest pain exists $(9,10)$. The patients without ST-segment elevation may undergo misdiagnosed or overestimated condition, including acute coronary syndrome. Therefore, we classified acute pericarditis by highlighting ECG features to prevent any possible failure to notice acute pericarditis: typical pericarditis (with ST elevation in ECG) or atypical pericarditis (PR depression in ECG).

\section{RESEARCH METHODOLOGY}

This study included 216 patients selected from the 2140 patients acute chest pain admitted into ED between 2015 and 2018. A written informed consent was obtained from each patient. The study protocol was approved Medicana International Ankara Hospital Ethics Committee. The study was conducted in accordance with the principles of Declaration of Helsinki.

216 patients were diagnosed acute pericarditis with 2 of the 4 criteria according to the 2015 European Society of Cardiology guideline of pericardial diseases. After then, two groups were retrospectively created by virtue of the presence or absence of typical ECG findings.

\section{Definition of Atypical ECG}

PR-segment depression in leads V5 to V6 in ECG (Figure 1).

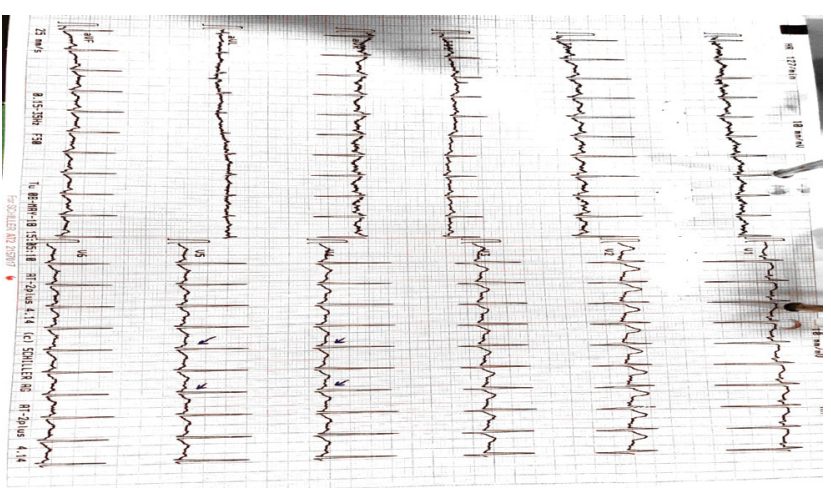

Figure 1) PR-segment depression in leads V5 to V6 in ECG

Definition of Typical ECG

Diffuse or regional concave ST elevations in ECG, same patient, next day after admission (Figure 2). One hundred patients (group I) had typical ECG, whereas 116 patients (group II) had atypical ECG changes.

The diagnostic examination included physical examination, blood tests (chemistry including renal and liver function tests and creatinine

Cag Hospital, Cardiology Clinic, and Medicana International Hospital, Cardiology Clinic, Ankara, Turkey

Correspondence: Dr Ersin Saricam, Cag Hospital, Cardiology Clinic and Medicana International Ankara Hospital, Sogutozu District 2165 St. No: 6 Sogutozu, Ankara, Turkey, Telephone+905324066440, fax+903122203170, e-mail saricamersin@yahoo.com

Received: June 27, 2018, Accepted: Jul 27, 2018, Published: Jul 31, 2018

OPEN $\bigcirc$ Access

This open-access article is distributed under the terms of the Creative Commons Attribution Non-Commercial License (CC BY-NC) (http:// creativecommons.org/licenses/by-nc/4.0/), which permits reuse, distribution and reproduction of the article, provided that the original work is properly cited and the reuse is restricted to noncommercial purposes. For commercial reuse, contact reprints@pulsus.com 
phosphokinase levels, C-reactive protein, cardiac troponin I, complete blood count, chest x-ray, electrocardiogram, echocardiogram, cardiac tomography imaging or magnetic resonance was used when indicated. 15 patients with typical ECG had non-infectious causes of pericarditis (post-cardiac injury syndrome, autoimmune causes, neoplastic, metabolic, traumatic and iatrogenic, drug-related).

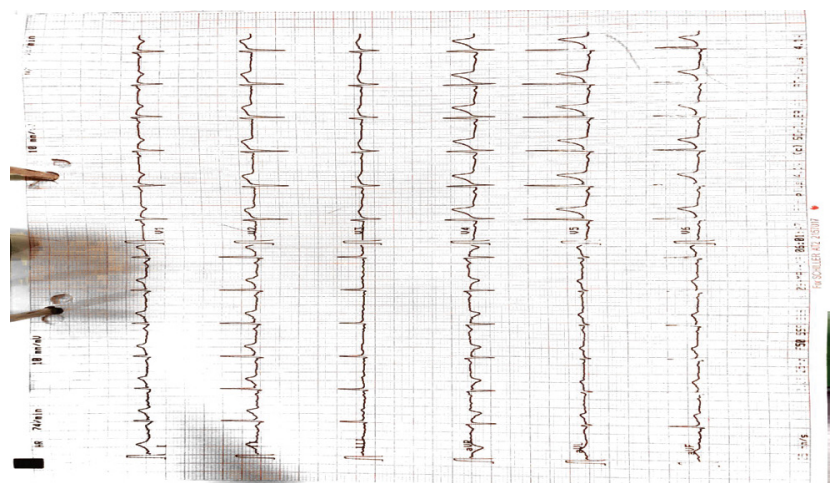

Figure 2) Diffuse or regional concave ST elevations in ECG, same patient, next day after admission

All of the patients with atypical ECG were accepted to have infectious pericarditis (viral idiopathic pericarditis).

The acute myopericarditis diagnosis was made considering typical acute pericarditis electrocardiography features and increased cardiac troponin I level $(\geq 1.0 \mathrm{ng} / \mathrm{ml})$. These patients were excluded.

The echocardiographic pictures were obtained by pericardial effusion, and other features. The two echocardiography readers were blinded to the diagnosis so as not to have any bias in interpreting the images. Standard transthorasic echocardiography was performed in left lateral decubitus position with Vingmed System Five Advantage echocardiography device (General Electric, USA) 2.5 MHz transducer and two-dimensional images (2D), M-mode and Doppler. Depth in operation was $20 \mathrm{~cm}$, dynamic range was 6. M-mode and 2-D images of left ventricle were taken based on the criteria of American Society of Echocardiography (11).

In group I, 10 patients underwent cardiac tomography because of suspected pulmonary embolism. 2 patients underwent cardiac magnetic resonance. 20 patients of group I (20/100) underwent coronary angiography, while 5 of the patients in group II were performed coronary angiography.

In therapy, while typical pericarditis group took nonsteroidal antiinflammatory drug plus colchicine, atypical pericarditis group took short time nonsteroidal anti-inflammatory drug.

\section{STATISTICAL ANALYSIS}

Statistical analyses were performed using SPSS software (version 17.0; SPSS Inc., Chicago, IL, USA). Continuous variables were presented as mean $\pm \mathrm{SD}$. A $p$ value of $<0.05$ was considered statistically significant.

\section{RESULTS}

Mean age of the patients with typical pericarditis was higher than atypical pericarditis patients $(\mathrm{p}<0.05)$ (Table 1$)$.

\section{TABLE 1}

\section{The characteristics of the patients}

\begin{tabular}{cccc}
\hline $\begin{array}{c}\text { Type of } \\
\text { pericarditis }\end{array}$ & $\begin{array}{c}\text { Typical pericarditis } \\
(\mathbf{n}=\mathbf{1 0 0})\end{array}$ & $\begin{array}{c}\text { Atypical pericarditis } \\
(\mathbf{n}=\mathbf{1 1 6})\end{array}$ & p-value \\
\hline Age (years) & $34.06 \pm 5.44$ & $31.56 \pm 6.81$ & $<0.05$ \\
Female & $18(\% 18)$ & $25(21.6 \%)$ & $>0.05$ \\
Male & $82(\% 82)$ & $91(78.4 \%)$ & \\
Troponin I (ng/ & $0.015 \pm 0.012$ & $0.006 \pm 0.010$ & $>0.05$ \\
ml) & $1.73 \pm 0.64$ & $0.44 \pm 0.49$ & $<0.05$ \\
CRP level (mg/L) & $16(16 \%)$ & $41(35.3 \%)$ & $<0.05$ \\
Recurrence & & & \\
\hline
\end{tabular}

The relationship between the electrocardiographic presentation and gender in patients with pericarditis was no statistically significant ( $p>0.05)$. Cardiac troponin I level among groups was statistically no significant $(p>0.05)$. Typical pericarditis group had higher CRP level than atypical pericarditis $(\mathrm{p}<0.05)$. Leucocyte counts was no statistically significant in both groups
( $p<0.05)$. Finally, the comparison pericarditis type and recurrence ratio were shown. Atypical pericarditis group had more recurrence rate than typical pericarditis $(p<0.05)$. In ECG following time, 10 patients of the atypical pericarditis (116 patients) had typical pericarditis features. If recurrence rates are to be compared, differences in the therapies received by the two groups may be important.

\section{DISCUSSION}

Acute pericarditis is a common disorder caused by the inflammation of the pericardium. The etiology of pericardial disease is often difficult to determine or remains idiopathic (12). The most frequent cause of acute pericarditis is idiopathic in developed countries (13). In general, the classification of the pericardial diseases can be made aetiologically or by duration. The aetiological classification of the pericardial diseases can be divided into infectious and non-infectious causes (5).

One of the diagnosis criteria of acute pericarditis is ECG changes. The ECG changes in acute pericarditis mainly show the inflammation of the epicardium (the layer directly surrounding the heart) because the parietal pericardium is electrically inert. Typical ECG changes in acute pericarditis occur diffuse ST elevations with reciprocal ST depression in aVR, and V1 in stage I. Widespread ST-segment elevation has been reported as a typical hallmark sign of acute pericarditis (6). Major differential diagnoses include acute coronary syndromes with ST-segment elevation and early repolarization. On the other hand, in 1980, Bruce MA and Spodick DH reported that stage I (typical ST elevation) changes had been observed in $80 \%$ of patients with pericarditis and informed about atypical electrocardiogram in acute pericarditis. Therefore, unfortunately, there is a possibility of missed diagnosis of atypical pericarditis cases. Likewise, Baljepally and Spodick (14) suggested that PR-segment deviation is the earliest ECG change in patients with acute pericarditis. Moreover, Pedley at al. reported that PR-segment depression is a potentially useful early electrocardiogram change in the evolution of acute pericarditis in ED (10). Our study demonstrated that 10 patients ECG features changed from atypical ECG to typical ECG pattern in Figures 1 and 2.

The elevation of PR segment in aVR and depression of PR in other leads, especially in leads V5 to V6, indicate atrial injury (8). The ST-segment elevation shows ventricular injury, whereas PR elevation or depression signifies right atrial injury and left atrial injury, respectively. Rossello at al. analyzed the patients with acute pericarditis and acute ST-segment elevation myocardial infarction. They reported that $\geq 7$ leads with ST-segment elevation and $\geq 0$ leads with PR-segment depression had $85.9 \%$ sensitivity and $85.3 \%$ specificity (15). Moreover, they found PR-segment depression in other leads was a more important indicator than PR-segment elevation in aVR lead. Therefore, both ST-segment elevation and PR-segment depression seen in ECG are important in terms of acute pericarditis diagnosis. Porela et al. suggested that PR segment analysis is a powerful tool in the differential diagnosis of myopericarditis and ST elevation myocardial infarction (16). Unfortunately, the patients with atypical ECG (PR-segment depression in ECG) have been ignored in ED. The patients with atypical ECG have significantly higher recurrence rate. The differences in the therapies received by the two groups might cause higher recurrence rate. Moreover, the patients with atypical ECG may be misdiagnosed or overestimated condition, including acute coronary syndrome. PR-segment recognition may confirm the correct diagnosis and prevent the unnecessary coronary angiography $(10,17)$. Therefore, we classified acute pericarditis cases according to electrocardiogram: typical and atypical pericarditis in ED practice. Thanks to this classification, overestimated diagnosis and ignored problem might be prevented. The pericardial involvement can be diagnosed, and early therapy may begin.

\section{STUDY LIMITATIONS}

When considering to diagnostic ECG criteria, PR depression is a specific but not sensitive one. Since study is a small-scale cross-sectional one it has got inherent limitations. If technical possibility was existing, the study would be more effective to divide the patients into localized or generalized pericarditis group according to imaging methods (CT, MRI).

\section{CONCLUSION}

We classified acute pericarditis as typical and atypical by highlighting ECG features to prevent any possible failure to notice acute pericarditis. It is recommended that the ECG features should be examined thoroughly, especially with a focus on ST-segment elevation besides PR-segment depression. 


\section{REFERENCES}

1. Tonini M, Melo DT, Fernandes F. Acute pericarditis. Rev Assoc Med Bras 2015;61(2):184-90.

2. Imazio M. Contemporary management of pericardial diseases. Curr Opin Cardiol 2012;27:308-17.

3. Imazio M, Gaita F. Diagnosis and treatment of pericarditis. Heart 2015;101:1159-68.

4. LeWinter MM. Clinical practice. Acute pericarditis. N Engl J Med 2014;371:2410-6

5. Adler Y, Charron P, Imazio M, et al. European Society of Cardiology (ESC). 2015 ESC Guidelines for the diagnosis and management of pericardial diseases: The Task Force for the Diagnosis and Management of Pericardial Diseases of the European Society of Cardiology (ESC) Endorsed by: The European Association for Cardio-Thoracic Surgery (EACTS). Eur Heart J 2015;36(42):2921-64

6. Spodick DH. Diagnostic electrocardiographic sequences in acute pericarditis: significance of PR segment and PR vector changes. Circulation 1973;48:575-80

7. Imazio M, Demichelis B, Parrini I, et al. Day-hospital treatment of acute pericarditis: A management program for outpatient therapy. J Am Coll Cardiol 2004;43(6):1042-6.

8. Bruce MA, Spodick DH. Atypical electrocardiogram in acute pericarditis: characteristics and prevalence. J Electrocardiol 1980;13(1):61-6.

9. Saricam E, Saglam Y. Potentially missed acute pericarditis: atypical pericarditis. Am J Emerg Med 2016;34(12):2451-3.
10. Pedley DK, Brett C, Nichol N. P-R segment depression: An early diagnostic feature in acute pericarditis: a telephone survey of UK accident and emergency departments. Eur J Emerg Med 2002;9(1):43-5.

11. Schiller NB, Shah PM, Crawford M, et al. Recommendations for quantitation of the left ventricle by two-dimensional echocardiography. American Society of Echocardiography Committee on Standards, Subcommittee on Quantitation of Two-Dimensional Echocardiograms. J Am Soc Echocardiogr 1989;2(5):358-67.

12. Khandaker MH, Espinosa RE, Nishimura RA, et al. Pericardial disease: diagnosis and management. Mayo Clin Proc 2010;85(6):572-93.

13. Imazio M, Gaita F, LeWinter M. Evaluation and treatment of pericarditis: A systematic review. JAMA 2015;314:1498-506.

14. Baljepally R, Spodick DH. PR-segment deviation as the initial electrocardiographic response in acute pericarditis. Am J Cardiol 1998;81:1505-6.

15. Rossello X, Wiegerinck RF, Alguersuari J, et al. New electrocardiographic criteria to differentiate acute pericarditis and myocardial infarction. Am J Med 2014;127(3):233-9.

16. Porela P, Kytö V, Nikus K, et al. PR depression is useful in the differential diagnosis of myopericarditis and ST elevation myocardial infarction. Ann Noninvasive Electrocardiol 2012;17(2):141-5.

17. Salisbury AC, Olalla-Gómez C, Rihal CS, et al. Frequency and predictors of urgent coronary angiography in patients with acute pericarditis. Mayo Clin Proc 2009;84(1):11-5. 